\title{
Development of the Ice Wall during the Construction of Vertical Mine Shafts
}

\author{
Anton A. Zharov ${ }^{(a)}$, Dmitry A. Mironov ${ }^{(b)}$ \\ (a) Bauman Moscow State Technical University, \\ Moscow, 105005, Russia, zharov a@bmstu.ru \\ (b) Bauman Moscow State Technical University, \\ Moscow, 105005, Russia, mironovda1@student.bmstu.ru
}

\begin{abstract}
The issue of creating and maintaining an ice wall (ICW) for mine shafts is considering in this article. The relevance of the study is due to the growing demand for such minerals as, for example, potash ore. Such ore is mined by the mine method, in which ICW is used to ensure the strength and waterproofing of the shaft. The main problem lies in the correct calculation of the required thickness of the ICW and cooling capacity, the choice of modes and freeze mechanism. The choice of different solutions affects capital and operating costs. The task is to assess the influence of the freezing pipe layout and the selected coolant temperature on the cost of capital and operating costs. Also, the analysis of the influence of the above factors on the process of soil freezing itself was carried out. Analytical methods of calculation and special software were used for the study. The reasons were considered that did not allow creating a closed ice wall, since they are often caused not by the choice of a circuit design and temperature regime, but by a violation of the drilling technology and installation of pipes. As a result, this article brings together the experience of creating an ice wall and provides a comparative analysis of various solutions.
\end{abstract}

Keywords: soil freezing, ice wall, mine shafts, chiller

\section{INTRODUCTION}

During the construction of vertical shafts in unstable unsaturated soil samples, the method of soil freezing is often used. The essence of the method lies in the fact that a coolant with a negative temperature circulates along vertical pipes located around the shaft with the same pitch from each other. Figure 1 shows the pipes mounting arrangement. As a result of the heat exchange process, the surrounding rocks are cooled and frozen, and a closed ice wall is formed, which ensures the strength of the lining and waterproofing the mine.

Before performing freezing work, a draft of ice wall is created, the initial data for which is a lithological section of the field with data on the thermophysical, mechanical properties of the underlying rocks and data on water infiltration in water-saturated layers. During the design, static and thermal calculations are performed, and the type of chillers used is determined. At present, freon or ammonia refrigeration machines (RM) are widely used to maintain ICW deep mine shafts. To ensure the safety and durability of equipment, various solutions with additives described in the work of Galkin (2019) are used as coolants. To increase 
efficiency, it is possible to reduce the temperature head in the condenser, which is described in the work of Shishov and Talyzin (2015). The choice of refrigerant also affects the efficiency of the chiller. In the works of Shishov et al. (2017) and Voronov et al. (2016), analysis algorithms are presented that allow you to choose the most efficient coolant. It is potentially possible to use a RM with carbon dioxide as a working fluid. An analysis of the effectiveness of such a facility is described in the work of Arkharov et al. (2017). To assess the thermodynamic efficiency, comparison with the ideal cycle is necessary. An example of such a cycle is presented in the work of Kolosov (2016). An analysis of energy losses due to an increase in entropy in the installation is presented in the work of Arkharov and Sychev (2006).

Currently, the method of soil freezing using solid carbon dioxide is widely used, which is described in the work of Nikolaev (2013), but this method has so far only found application for urban construction in shallow depths. In the future, it is possible to use cold storage systems with the generation of solid carbon dioxide at night. A thermodynamic interpretation of such a problem is presented in the work of Arkharov et al (2009).

Since the middle of the last century, liquid nitrogen has been used as a source of cold. This method has found application in cases where small volumes of soil are subject to freezing, when it is required to freeze in an extremely short time, or it is required to freeze an area with quicksand, which is difficult to freeze.

Based on the results of static calculations, the required thickness of the ICW is determined based on the conditions of strength, yield strength, or based on the maximum permissible deformations of the pipes . Methods for static calculations are described in the textbooks of Andersland (2013) and Trupak (1979). The analysis of static calculation methods is presented in the new works of Levin, Semin and Plekhov (2018). The output data of heat engineering calculations are the required cooling capacity of the refrigeration machine, the distribution of the coolant temperatures along the pipe height, the temperature field in the rocks, and the freezing mode and time. These issues are extensively covered in the book by Trupak (1983).

The influence of the selected coolant temperatures on the strength of rocks and the freezing process is also described in detail, but in the existing works there is very little information about the influence of the geometry of the arrangement of the freezing pipes on the freezing process and on the cost of capital and operating costs. In addition, there is no description of the effect of the selected temperature of the brine on the cost of costs and on the operating modes of refrigeration machines, since a change in the required temperature of the brine leads to a change in the boiling point of the coolant and, consequently, to a change in the cooling capacity and power consumption of the refrigerant. These are the issues discussed in this article. Additionally, methods are described, with the help of which it is possible to achieve a reliable ICW taking into account modern technologies for monitoring well drilling and monitoring the freezing process. 


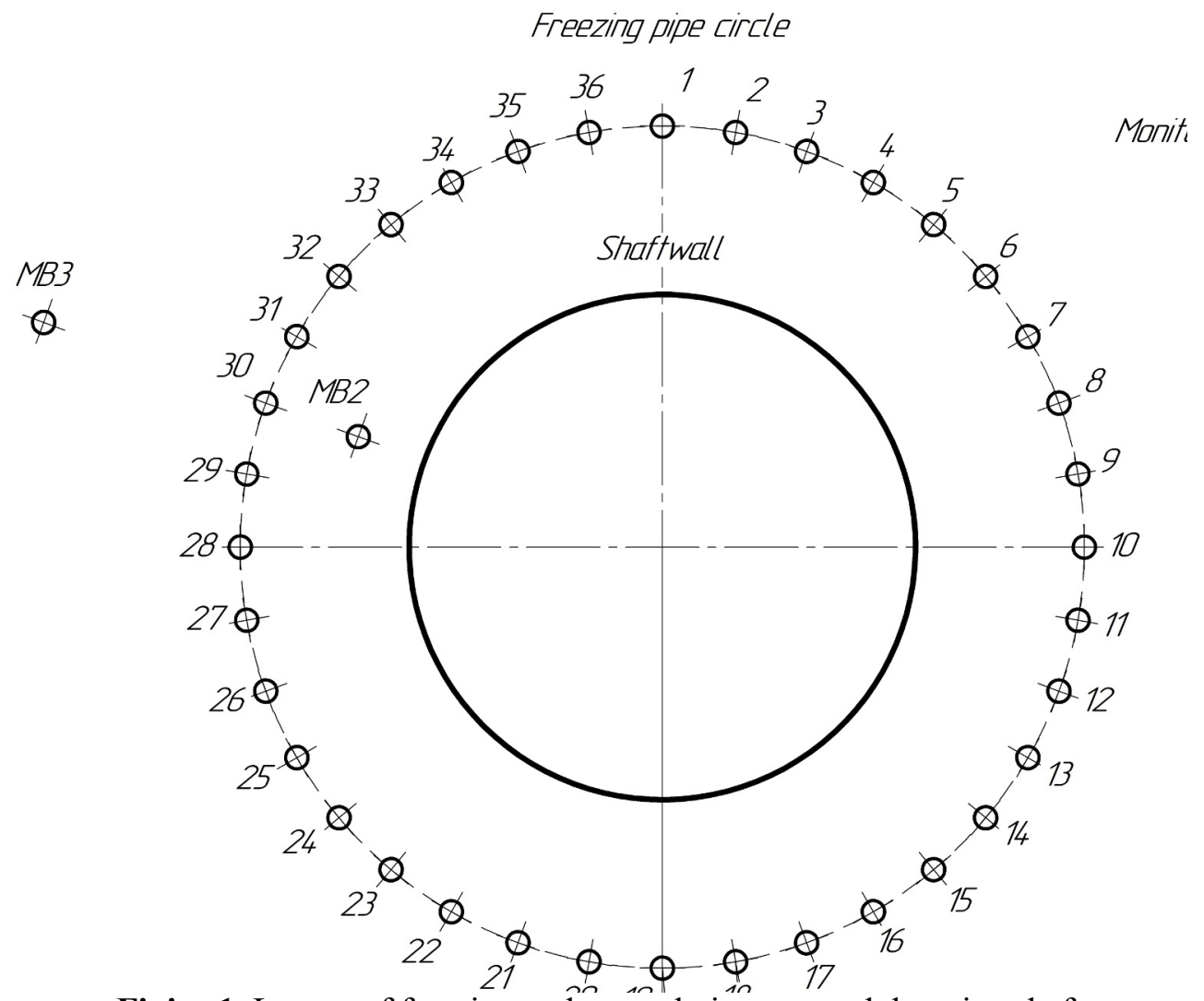

Figjre 1. Layout of freezing and control pipes around the mine shaft

\section{MAIN CHAPTER}

\section{Problem statement}

It is necessary to consider various options for a single-row arrangement of freezing pipes, which differ from each other in different distances between the pipes with the same diameter of the circle on which they are located, and different options for the temperatures of the brine and evaluate the influence of these factors on the cost and capital and operating costs of installation and provision work of the complex for the maintenance of ICW. Within the framework of this work, the complex for maintaining ICW is considered as a combination of refrigerating machines and freezing pipes.

\section{Methods}

To solve the problem, various schemes were drawn up based on existing recommendations.

According to the works of Trupak (1979 and 1983), there is a recommended ratio (1) between the diameter of the mine shaft in the penetration $D$, the required 
thickness of the ICW $E$ and the diameter on which the freezing pipes $D_{1}$ are located:

$$
D_{1}=D+0,6 \cdot 2 \cdot E
$$

The pipes should be located in such a way that the ICW reaches the boundaries of the mine shaft, but the core of the shaft is not frozen.

There are also norms according to which the distance between two freezing pipes must be from 1 to 1.5 meters, which is described in a handbook edited by Trupak (1980). With increasing distance, the number of pipes decreases, but at the same time, the reliability of the ICW decreases.

The brine temperature determines the temperature of soils and, consequently, their strength characteristics, which is described in the textbook of Tsytovich (2009). The standard temperature range of the brine is -40 to $-30^{\circ} \mathrm{C}$. Typically, lower temperatures within the specified range are required if the groundwater has a high salt content. At the same time, with a decrease in the temperature of the brine by 1 ${ }^{\circ} \mathrm{C}$ in this range, there is a decrease in cooling capacity by about $3.3 \%$ and a decrease in the power consumption of the chiller by an amount from 1 to $2 \%$.

To calculate the parameters of the RM, the characteristics of the compressor and heat exchangers obtained from the programs for the selection of equipment from manufacturers were used.

The following algorithm was used for the calculation: the diameter was set on which the pipes are located; the number of pipes was set; the distance between the pipes was determined; the temperature of the brine was set; the parameters of the RM were calculated; the amount of RM was determined; determined the cost of capital and operating costs.

\section{Results}

A comparison between different layouts of freezing pipes and different temperature regimes was made for the following input data:

1) The depth of freezing of rocks is 750 meters.

2) The diameter of the mine shaft in the sinking is 9 meters.

3) The required maximum ICW thickness is 6.5 meters.

4) For all schemes, regardless of the temperature of the coolant, the following identical freezing mode is adopted (this assumption is acceptable, since approximately $60 \%$ of the total cooling capacity is spent on freezing moisture in the soil, $20 \%$ is spent on cooling water and ice, and $20 \%$ is spent on cooling dry particles):

- $\quad$ Active phase I: cooling capacity $5600 \mathrm{~kW}$; duration - 150 days;

- $\quad$ Active phase II: cooling capacity $3800 \mathrm{~kW}$; duration - 320 days;

- $\quad$ Passive phase: cooling capacity $2500 \mathrm{~kW}$; duration - 123 days;

The difference between the active phases and the passive phase lies in the fact that during the active phases, the soil freezes, and during the passive phase, the main part of the ICW is only supported, while the peripheral part begins to thaw. Defrostation is necessary to enable the erection of a permanent external concrete lining. The time of the passive phase is determined by the time of erection of the 
permanent support. Also, the difference lies in different temperatures of the brine at the inlet to the freezing pipes and, accordingly, in different boiling points of the refrigerant of refrigerating machines.

5) RM is built on the basis of a vapor compression refrigeration cycle. It consists of a compressor station with three semi-hermetic screw compressors, an air oil cooler, an air condenser, an economizer heat exchanger, and a plate evaporator.

6) At the moment, the market value of one chiller with a cooling capacity of $362 \mathrm{~kW}$ and the resulting temperature of the brine minus $34{ }^{\circ} \mathrm{C}$ is $342,000.00 €$; the cost of drilling a well and installing a freezing pipe is $612,000.00 €$; the electricity tariff is $0.0685 € /(\mathrm{kWh})$.

Table 1 and Figure 2 show the calculation results.

\begin{tabular}{|c|c|c|c|c|}
\hline $\begin{array}{c}\text { Brine temperature } \\
\text { during active freezing } \\
\text { phase, }{ }^{\circ} \text { C }\end{array}$ & -38 & -37 & -36 & -34 \\
\hline $\begin{array}{c}\text { Brine temperature } \\
\text { during passive freezing } \\
\text { phase, }{ }^{\circ} \text { C }\end{array}$ & -30 & -29 & -28 & -28 \\
\hline $\begin{array}{c}\text { Cooling capacity of one } \\
\text { RM during the active } \\
\text { phase, } \mathrm{kW}\end{array}$ & 316 & 327 & 338 & 362 \\
\hline $\begin{array}{c}\text { Cooling capacity of one } \\
\text { RM during the passive } \\
\text { phase, } \mathrm{kW}\end{array}$ & 411 & 423 & 436 & 436 \\
\hline $\begin{array}{c}\text { Power consumption of } \\
\text { one RM during active } \\
\text { phase, } \mathrm{kW}\end{array}$ & 326 & 332 & 337 & 346 \\
\hline $\begin{array}{c}\text { Cooling capacity of one } \\
\text { RM during the passive } \\
\text { phase, } \mathrm{kW}\end{array}$ & 368 & 374 & 379 & 379 \\
\hline $\begin{array}{c}\text { Calculated number of } \\
\text { RM, active phase I }\end{array}$ & 17,7 & 17,1 & 16,6 & 15,5 \\
\hline $\begin{array}{c}\text { Calculated number of } \\
\text { RM, active phase II }\end{array}$ & 12 & 11,6 & 11,2 & 10,5 \\
\hline $\begin{array}{c}\text { Calculated number of } \\
\text { RM, passive phase }\end{array}$ & 6 & 5,9 & 5,7 & 5,7 \\
\hline Required number of RM & 18 & 18 & 17 & 16 \\
\hline $\begin{array}{c}\text { The total electricity } \\
\text { consumed by the RM } \\
\text { during three phases of } \\
\text { freezing, kW *h }\end{array}$ & 57513402,2 & 56623601,8 & 55613195,32 & 53578233,21 \\
\hline $\begin{array}{c}\text { Number of freezing } \\
\text { pipes }\end{array}$ & 36 & 38 & 40 & 44 \\
\hline $\begin{array}{c}\text { Freezing pipes circle } \\
\text { diameter, m }\end{array}$ & 17 & 17 & 17 & 17 \\
\hline
\end{tabular}




\begin{tabular}{|c|c|c|c|c|}
\hline $\begin{array}{c}\text { Distance between two } \\
\text { neighbour pipes, } m\end{array}$ & 1,48 & 1,41 & 1,34 & 1,21 \\
\hline Total cost of all RM, $€$ & 6156000,00 & 5156000,00 & 5814000,00 & 5472000,00 \\
\hline Total cost of all pipes, $€$ & 22032000,00 & 23256 & 24480 & 26928 \\
& 000,00 & 000,00 & 000,00 \\
\hline Electricity cost, $€$ & 3939668,05 & 878716,72 & 3809503,88 & 3670108,97 \\
\hline Total cost, $€$ & 32127 & 33290 & 34103 & 36070 \\
& 668,05 & 716,72 & 503,88 & 108,97 \\
\hline
\end{tabular}

Table 1. Calculation of capital and operating costs for ICW under various modes

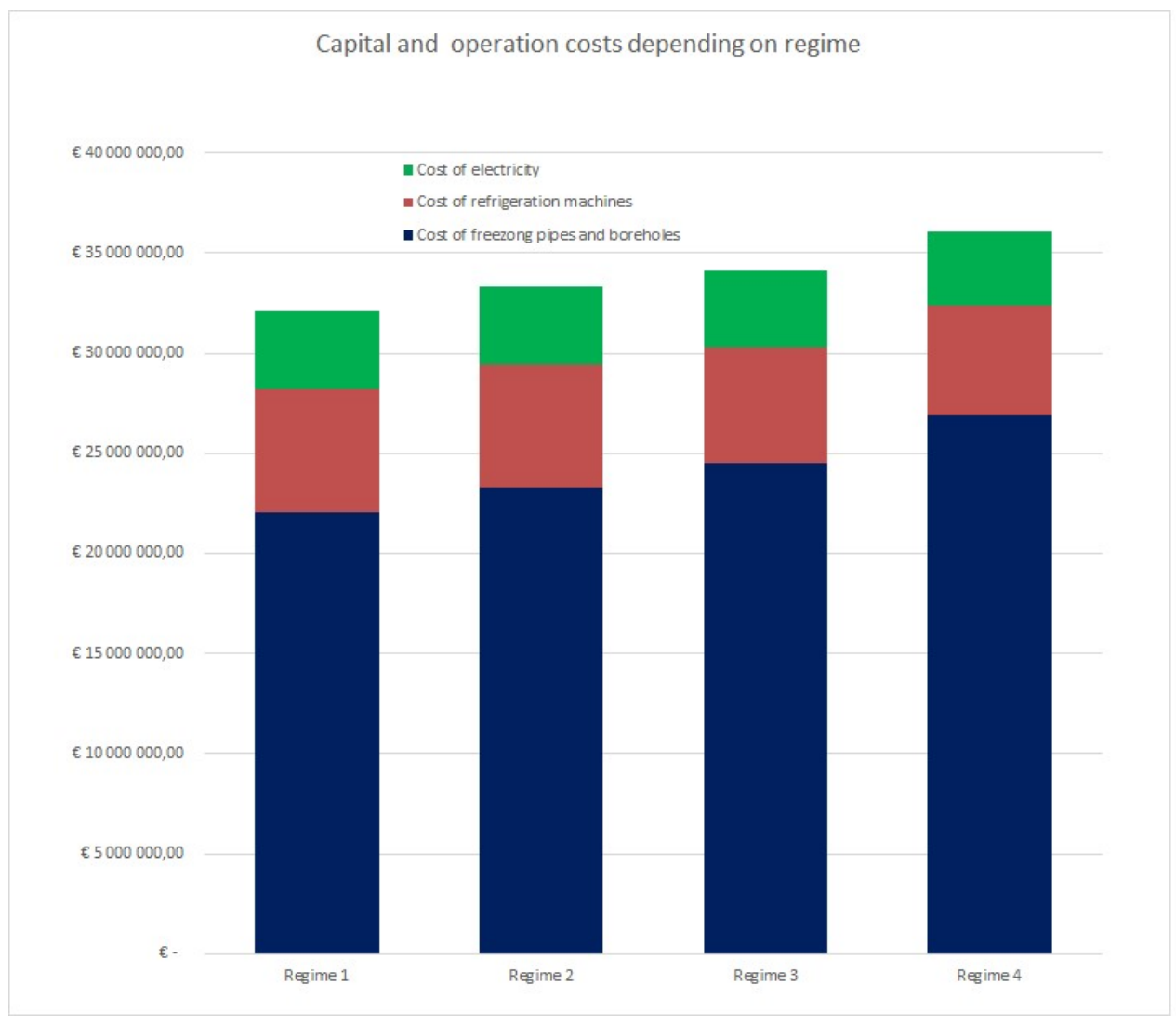

Figure 2. Cost sharing depending on the mode

\section{Results and discussions}

Based on the results of calculations for each project for the creation of ICW, after static and thermal calculations, it is possible to choose the optimal scheme and freezing mode and at the same time estimate the capital and operating 
costs. It should be borne in mind that most often it is not the temperature regime or the layout of the pipes that determine the success of creating a closed ICW. Based on the soil freezing projects carried out over the past 40 years, the following factors can be identified that affect the reliability of the ICW:

- $\quad$ Need to control the deviation of the freeze pipe wells throughout the depth to avoid areas where the distance between the pipes is too great;

- Ultrasonic monitoring of ICW continuity together with control of temperatures in control-thermal wells gives a complete picture of ICW formation and makes it possible to identify unfrozen areas even before the moment the shaft is flooded;

- $\quad$ The correctness of design calculations depends primarily on the accuracy of determining the composition of soils and their properties, and only secondarily on the methods used for calculations: analytical or numerical.

\section{CONSLUSION}

According to the study results, the cost of capital expenditures for RM is from 15 to $19 \%$ of the total cost of providing health care products. The capital costs of the freezing pipes account for the majority of the cost, namely 69 to $75 \%$ of the total cost. The share of electricity costs is from 10 to $12 \%$, but this work does not yet take into account the electricity consumed by the pumps, since it depends to the greatest extent only on the consumption of the coolant, i.e. cooling capacity, provided that the temperature difference of the coolant across the pipes is the same and is $2 \mathrm{~K}$.

Based on the calculation results, the following conclusions can be drawn:

a) Providing the complex for the maintenance of the ICW with a reserve chiller has little effect on the total cost (increases the cost by about 1\%), but this solution can avoid emergency situations when additional refrigeration capacity is required, for example, in the following cases: high ambient temperature; discrepancy between real thermophysical properties of soils and properties determined experimentally before the start of work; detection of quicksands in the ground, etc.

b) Due to the fact that the share of electricity consumed by the RM is from 10 to $12 \%$, it does not make sense to perform a detailed calculation of energy consumption at different condensing temperatures of the refrigerant in the RM, since these fluctuations will have little effect on the result.

c) An increase in the number of pipes affects the total cost of the complex more significantly than an increase in the number of RMs (adding one pipe increases the cost of the complex by about $1.7 \%$ ), but with an increase in the number of pipes, the reliability of the ICW increases in the event of several failures. In the work of Levin, Kolesov and Semin (2016) it is shown that if one or two pipes are damaged, the thickness of the ICW will not decrease, it will only take more time to reach it. On the other hand, compared with the 70s and 80s of the last century, there is a trend to increase the distance between pipes from 1 meter to 1.4 meters and even 1.5 meters. This trend is due to the fact that at present, with the help of modern drilling control tools, it is possible to create a well with a tolerance for deviation from vertical to 0.6 meters at depths of up to 1000 meters. In the $70 \mathrm{~s}$ and $80 \mathrm{~s}$, the deviation of the well from the vertical at a depth of 1000 meters with 
standard drilling could be 2.5 meters, which could lead to the formation of nonfreezing windows between the pipes.

\section{INSTRUMENTATION SYMBOLS AND IDENTIFICATION}

$\begin{array}{ll}E & \text { ICW depth (m) } \\ D & \text { Main shaft diameter (m) }\end{array}$

$D_{1} \quad$ Freezing pipes circle diameter $(\mathrm{m})$

\section{REFERENCES}

1. O.B. Andersland, B. Ladanyi, (2013). An introduction to frozen ground engineering. Springer Science \& Business Media.

2. A. M. Arkharov, A. I. Leont'ev, V.V. Sychev, I.A. Arkharov, E.N. Krizhanovskaya, P.V. Kustov, (2009). Problem of cold accumulation as a matter of energy saving and optimization of energy consumption. Chemical and Petroleum Engineering, 45.

3. A.M. Arkharov, V.V. Sychev, (2006). Actual energy loss due to entropy generation in low-and high-temperature machines and plants. Chemical anld Petroleum Engineering, 42(1-2), 31-41.

4. M.A. Kolosov, (2016). Theorem of Ideal Cycles of Refrigerating Machines. Chemical and Petroleum Engineering, 51(9-10), 674-682.

5. V.V. Shishov, M.S. Talyzin, (2015). Improving the energy efficiency of refrigeration plants by decreasing the temperature difference in air-cooled condensers. Thermal Engineering, 62(9), 652-655.

6. A.M. Arkharov, V.V. Shishov, M.S.Talyzin, (2016). The selection of the optimal refrigeration system for the store based on the entropy-statistical analysis of low-temperature refrigeration cycles. Refrigeration technology, (3), 30-34.

7. A.M. Arkharov, V.V. Shishov, M.S. Talyzin, (2017). Entropy-statistical analysis of low-temperature transcritical cycles of carbon dioxide. Engineering Journal: Science and Innovation, (3), 1-14.

8. W. Bjorn, (2014). Modern technology of rock freezing on the example of two objects under construction, consisting of five vertical main shafts. Mining Journal, (9), 65-67.

9. I.S.Vakulenko and P.V. Nikolaev (2015). Analysis and development prospects of a method for artificial freezing of rocks in underground construction. Mining informational and analytical bulletin (scientific and technical journal) (3).

10. V.V. Davydov, E.G. Duda, A.I. Kaveshnikov, E.Ya. Kipko and others. Handbook on the construction of mine shafts by special methods / M.; Nedra, 1980. - $391 \mathrm{p}$.

11. V.A. Voronov, P.Yu. Zhurlova, D.Yu. Zabolotny, S.S. Sheremetyev, Selection of mixed coolants for vapour compression refrigeration machines and heat pumps. Politechnical student journal of BMSTU. M, (3). (2016). 
12. M. L. Galkin, N.G. Manokhina, Additives for improving industrial safety of equipment cooling and heating systems. Occupational safety in industry, (12), 46-52 pp. (2019).

13. L.Yu. Levin, E.V. Kolesov, M.A. Semin, Investigation of the dynamics of the ice wall under conditions of damage to the freezing pipes during the sinking of mine shafts. Mining information and analytical bulletin (scientific and technical journal), (11). (2016).

14. L.Yu. Levin, M.A. Semin, O.S.Parshakov, Mathematical prediction of the thickness of the ice wall during shaft sinking. Journal of Mining Sciences, (5), 154-161.(2017).

15. L.Yu. Levin, M.A.Semin, O.A. Plekhov, Comparative analysis of the existing methods for calculating the thickness of the ice facility of the construction shaft shaft. Construction and Architecture, 9(4), 93-103. (2018).

16. O.A. Mishedchenko, Analysis of the experience of sinking vertical shafts at the Lubin copper deposit in Poland using the method of freezing rocks. Mining information and analytical bulletin (scientific and technical journal), (3). (2007).

17. P.V. Nikolaev Experience and prospects for the development of resourcesaving technologies for soils freezing in urban underground development // Mining information and analytical bulletin (scientific and technical journal). 2014. №. 2.

18. N.G. Trupak, 1979 Soils freezing of in underground development. Nedra.

19. N.A. Tsytovich, Mechanics of frozen soils. Instructional medium. M., "Higher. School" 1973.

20. V.V. Shishov, Refrigeration machines with compressor steam extraction at intermediate pressure (units with economizer). Kholodilnaya tekhnika magazine, (9), 63-63 pp. (2006).

21. V.V. Shishov, A.I. Verkhovny, , M.K. Vasiliev, R.R. Sakhapov, The choice of coolant for the refrigeration machine based on entropy-statistical analysis. Kholodilnaya tekhnika magazine, (5), 38-41. (2017).

22. V.V. Shishov, M.S. Talyzin, Practical application of the entropy-statistical method for the analysis of refrigeration cycles. Refrigeration technology, (3), 25. (2015). 